\title{
Near edge K-Shell X-ray absorption fine structure (NEXAFS) Analysis of Co (II) Mixed Ligand Complexes with Schiff base and 3-hydroxy Picolinamide Ligands
}

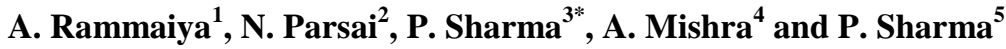 \\ ${ }^{1}$ Dept. of Physics, Bherulal Patidar, Govt. P. G. college, Mhow \\ ${ }^{2}$ Shri Vaishnav Institute of Management, Indore \\ ${ }^{3}$ Dept. of Physics, Govt. Autonomous Holkar Science College, Indore \\ ${ }^{4}$ Shool of Physics, Devi Ahilya University, Indore \\ ${ }^{5}$ School of Chemistry, Devi Ahilya University, Indore
}

Available online at: www.isroset.org

Accepted: 09/Jul/2018, Online: 31/Aug/2018

\begin{abstract}
X-ray absorption fine structure (XAFS) at the K-edge of copper has been studied in some cobalt (II) mixed ligand complexes having Schiff base and 3 hydroxy Picolinamide ligands. The study can be used to yield useful and important information about the molecular structure of the complexes. The X-ray absorption measurements have been performed at BL-8 Dispersive EXAFS beamline at $2.5 \mathrm{GeV}$ Indus-2 Synchrotron Source at RRCAT, Indore, India. The data obtained has been processed using EXAFS data analysis program Athena. From the experimental measurements, the energies of the K absorption edge, chemical shifts, edge-widths, shifts of the principal absorption maximum in the complexes have been estimated. The data obtained from these studies have been utilized to estimate effective nuclear charge and percentage covalency.
\end{abstract}

Keywords: XAFS, Athena, Absorption, Chemical shift.

PACS: 61.05.cj

\section{INTRODUCTION}

The X-ray absorption spectra at the K-edge of cobalt of a series of mixed ligand cobalt complexes, having Schiff base and 3 hydroxyPicolinamideligands, have been investigated. It is an established fact that the X-ray spectra are best recorded using X-rays from synchrotrons. The $2.5 \mathrm{GeV}$ synchrotron, called Indus-2, has now been commissioned in India at Raja Ramanna Centre for Advanced Technology (RRCAT), Indore, which gives very high intensity X-rays. The beamline which is suitable for recording $\mathrm{X}$-ray absorption spectra, called BL-8 dispersive EXAFS beamline, has been developed at the Indus-2 synchrotron source. Hence, we thought it proper to study those complexes using synchrotron radiation. We sent a proposal for allotting beam time to us for recording the spectra of these complexes. The beam time was allotted to us and we recorded the Co K-absorption spectra of the series of the cobalt complexes at the Indus-2 dispersive EXAFS beamline. The five studied complexes are given in table 1.

\section{EXPERIMENTAL}

In the present work XANES spectra of the five mixed ligand cobalt complexes have been recorded using Indus-2 synchrotron dispersive EXAFS beam line at RRCAT, Indore. In the dispersive mode, a bent crystal polychromator is used, to select a band of energy from the white synchrotron beam, which is horizontally dispersed and focused on the sample. The transmitted beam intensity from the sample is recorded on a position sensitive CCD detector, thus enabling recording of the whole EXAFS spectrum around an absorption edge in a single shot.

The energy calibration of the beamline for a particular setting of the polychromator can be done using the method outlined by Gaur et al. ${ }^{1}$. For calibration, the absorption spectra of two standards, whose absorption edge energies are well established, are recorded. The first edge energy should be in the beginning and the second edge energy should be at the end of the range of the spectra to be recorded. For the measurement of absorption spectra of cobalt (II) mixed ligand complexes the CCD channels are calibrated at the cobalt K-edge of $7708.9 \mathrm{eV}$. The 
absorption spectra and corresponding derivative spectra of cobalt foil and $\mathrm{Dy}_{2} \mathrm{O}_{3}$ pellet were recorded. The absorption edges of cobalt foil and $\mathrm{Dy}_{2} \mathrm{O}_{3}$ pellet are found to appear at CCD channel numbers of 788 and 1154, respectively. From the known values of cobalt and $\mathrm{Dy}_{2} \mathrm{O}_{3} \mathrm{~K}$-edges at $7708.9 \mathrm{eV}$ and $7790.1 \mathrm{eV}$, respectively ${ }^{2,3}$, the $\mathrm{CCD}$ channels are calibrated with respect to energy. A dispersion of $0.2218 \mathrm{eV}$ per channel is obtained in the present setting.

\section{RESULTS}

The intensities $I_{0}$ and $I_{t}$, are obtained as the CCD outputs without and with the sample respectively. Using the relation, $\mathrm{I}_{\mathrm{t}}=\mathrm{I}_{0} \mathrm{e}^{-\mu \mathrm{x}}$, where $\mu$ is the absorption coefficient and $\mathrm{x}$ is the thickness of the absorber, the absorption $\mu(\mathrm{E})$ corresponding to the photon energy (E) are obtained. The experimental data has been analyzed using the available computer software package Athena.

The XAFS spectra in the region $-100<\mathrm{E}<600 \mathrm{eV}$, indicating positions of the absorption edges $\mathrm{K} 1$ and $\mathrm{K} 2$ and principal absorption maximum $\mathrm{A}$ are shown in fig. 1 . The first derivatives of the XAFS spectra in this region, indicating positions of the absorption edges $\mathrm{K} 1$ and $\mathrm{K} 2$ and principal absorption maximum $\mathrm{A}$ are shown in fig. 2. First peak in the derivative spectra gives the position of first inflection point, i.e., the $\mathrm{K} 1$-absorption edge $\left(\mathrm{E}_{\mathrm{k} 1}\right)$ and second peak gives the second inflection point, i.e., the K2absorption edge $\left(\mathrm{E}_{\mathrm{k} 2}\right)$. The position where the derivative is zero, gives the position of principal absorption maxima $\left(\mathrm{E}_{\mathrm{A}}\right)$. The results of the energies of the $\mathrm{K}$-absorption edges $\left(\mathrm{E}_{\mathrm{k} 1}\right.$ and $\mathrm{E}_{\mathrm{k} 2}$ ) and the energies of principal absorption maximum A $\left(\mathrm{E}_{\mathrm{A}}\right)$ of cobalt in metal and its five complexes are presented in table 2 . The chemical shifts (in $\mathrm{eV}$ ) of the $\mathrm{K}$ absorption edge of cobalt in the complexes are also given in table 2. For all the complexes the distance (in $\mathrm{eV}$ ) of the principal absorption maximum $A$ with respect to the respective $\mathrm{K}$-absorption edge have also been computed and are collected in the same table. It can be readily seen from table that cobalt K-edge is found to be shifted towards the high energy side in all the five complexes, as compared to the cobalt metal K-absorption edge. Following the principal absorption maximum $\mathrm{A}$, there are distinct EXAFS features extending up to $300 \mathrm{eV}$ on the high energy side of the $\mathrm{K}$ absorption edge.

\section{DiscuSSIONS}

\section{A. Splitting of the edge}

The cobalt K-edge, as shown in fig. 1, has been found to split into two components, i.e., $\mathrm{K} 1$ and $\mathrm{K} 2 \mathrm{in}$ all the complexes. The splitting is seen clearly when the first derivative of these spectra, given in fig. 2, are examined. The values of $E_{K 1}$ and $E_{K 2}$ for the $K$-absorption edge of cobalt in its complexes are given in table 2 . These have been determined as the energies of the first two peaks in the derivative spectra.
The K-edge of cobalt, as shown in fig. 1, has been found to split into two components, i.e., $\mathrm{K} 1$ and $\mathrm{K} 2$, with a shoulder in between, in all the complexes. This feature shows that cobalt is in oxidation state +2 in these complexes.

\section{B. Position of the edge}

As already pointed out above, in case of cobalt complexes, the absorption edge is found to split in two components $\mathrm{K} 1$ and $\mathrm{K} 2$. The inflection point of the first rise in the absorption edge corresponds to the binding energy corresponding to that edge, i.e., the inflection point on the $\mathrm{K} 1$ edge corresponds to the binding energy $\mathrm{E}_{0}$ or $\mathrm{E}_{\mathrm{K}}$ of the $\mathrm{K}$ level.

In the present work to determine the exact position of the inflection point, the first derivative of the $\mu(\mathrm{E})$ versus $\mathrm{E}$ curve has been computed. The first maximum on the first derivative curve gives the position of the inflection point and hence the position of the $\mathrm{K} 1$ absorption edge. If there is any difficulty in measuring the position of the edge from the first derivative spectra, then the second derivative of the $\mu(\mathrm{E})$ versus $\mathrm{E}$ curve is used for this purpose. The first zero crossing point on this second derivative curve also gives the position of the $\mathrm{K} 1$ absorption edge correctly.

For the K-absorption edge, the position of the edge is written as $E_{K}$ in $e V$. The values of $E_{K}$ (i.e., $E_{K 1}$ ) for the $K$ absorption edge of cobalt in its complexes studied are given in table 2.

\section{Chemical shift}

The K-absorption edge of cobalt has been found to be shifted towards the high energy side in all the complexes studied as compared to the K-absorption edge in the metal. The shifts of the K-absorption edge of cobalt in the complexes with respect to that of cobalt metal have been determined according to the eqn.

$$
\Delta \mathrm{E}_{\mathrm{K}}=\mathrm{E}_{\mathrm{K}} \text { (complex) }-\mathrm{E}_{\mathrm{K}} \text { (metal) }
$$

For computing the chemical shift the value of $\mathrm{E}_{\mathrm{K}}$ (Co metal) has been taken as $7708.01 \mathrm{eV}$. The order of the chemical shifts as indicated by their values from table 2 , has been found to be as follows:

As is well known, an ionic bonding enhances the chemical shift, whereas a covalent bonding suppresses it. In general, the chemical shift reflects the ionic character of the complex, more the chemical shift, more the ionic character. Hence, the above order may also be taken as representative of the relative ionic character of the bonding in these complexes. As the complex $\mathrm{C}[\mathrm{Co}(\mathrm{HPA})(\mathrm{MPIPMBD})] \mathrm{H}_{2} \mathrm{O}$ is showing highest chemical shift in the series compared with other complexes, hence, it should have the maximum ionic character amongst the studied complexes.

The compounds having cobalt in oxidation state in +1 show chemical shifts less than $5 \mathrm{eV}$ while those having cobalt in oxidation state in +2 show chemical shifts more than $5 \mathrm{eV}^{4,5}$. In table 2, all the five complexes have the 
values of chemical shifts between $6.44-09.10 \mathrm{eV}$. Hence, on the basis of values of the chemical shifts, all the complexes are found to have cobalt in oxidation state +2 .

\section{Effective nuclear charge (ENC)}

Following Gianturco et al. ${ }^{6}$, Gupta and Nigam ${ }^{4,5}$ and Nigam and Gupta ${ }^{7,8}$ have outlined the method of determining the effective nuclear charge on ions from the measurement of the chemical shifts.

If the binding energies of $\mathrm{K}$ electron of cobalt in different oxidation states are determined, one can find from the difference in binding energies of the neutral atom and the ionized atom, the so called theoretical shifts in the X-ray absorption edge.

The theoretical shifts are plotted against the oxidation number. From this graph, the effective nuclear charge on cobalt in its complexes has been determined and the results have been presented in table 2 .

\section{E. Principal absorption maximum}

In table 2, we have also included the data for the principal absorption maximum $\mathrm{E}_{\mathrm{A}}$ for the complexes. This maximum corresponds to the $1 \mathrm{~s} \rightarrow 4 \mathrm{p}_{\mathrm{z}}$ transition as well as to the transitions to the continuum states. It has been observed that with respect to cobalt metal, the value of $E_{A}$ isshifted towards the higher energy side. For the complexes mentioned in table 2, the energy range of chemical shift in these complexes is between $6.44-09.10 \mathrm{eV}$ while the range for shift of principal absorption maximum is between 17.32 $-18.57, \mathrm{eV}$. Hence, on the basis of the shift of the principal absorption maximum also it can be inferred that cobalt is in +2 oxidation state in these complexes.

\section{F. Edge-width} have been reported.

In table 2 , the values of the edge-width $\left(\mathrm{E}_{\mathrm{A}}-\mathrm{E}_{\mathrm{K} 1}\right)$

The edge-width of the K-absorption edges increase with the increase in covalent character of the bonds provided other factors like molecular geometry etc remain the same. In the present work, edge-width of cobalt complexes is observed to vary from 8.89 to $11.91 \mathrm{eV}$. The order of the edge-width is in the reverse order of chemical shift of the complexes approximately. The reverse order represents that the edge-width is inversely proportional to ionic character for this series.

\section{G. Percentage Covalency}

Covalency is the relative tendency or infact exhibition extent of the covalent character in a chemical compound while still also possessing some ionic character. Percentage covalency of the complex is the ratio of Edge width to Atomic number of absorbing atom. The chemical shift can also be treated as a measure of covalency. The chemical shift is governed by covalent character of the bond. As the chemical shift goes on increases, percentage covalency decreases. A theoretical graph is plotted between the calculated value of binding energy of 1s electron using Clementi's result of atomic function and percentage covalency. This graph is used to calculate the percentage covalency of the bonds. The percentage covalency of metal ligand bonding in cobalt complexes is observed to vary from 32.92 to 44.11 . This shows that as chemical shift increases percentage covalency decreases.

\section{Conclusions}

X-ray absorption spectra of mixed ligand cobalt complexes at the K-edge of cobalt have been recorded at the recently developed EXAFS beamline set-up at the Indus-2 synchrotron source at RRCAT, Indore.

The K-edge has been found to split into two components, i.e., $\mathrm{K} 1$ and $\mathrm{K} 2$ in all of these complexes. The energies of $\mathrm{K} 1$ edge $\left(\mathrm{E}_{\mathrm{K} 1}\right), \mathrm{K} 2$ edge $\left(\mathrm{E}_{\mathrm{K} 2}\right)$, principal absorption maxima $\left(\mathrm{E}_{\mathrm{A}}\right)$ and EXAFS maxima and minima have been reported. Hence, the shift of the K1-edge (chemical shift) has been obtained.

The order of chemical shift may be taken as representative of the relative ionic character of the bonding in these complexes. The chemical shift has been used to determine the effective nuclear charge on the absorbing atom. The values of the chemical shifts suggest that cobalt is in oxidation state +2 in all of the complexes. The shift of the principal absorption maximum has been obtained. The order of shift of principal absorption maximum for the complexes is in reverse order of the chemical shift approximately. The reverse order represents that the shift of the principal absorption maximum is inversely proportional to ionic character for this series. The edge-width has also been obtained for all the complexes. The order of the edge-width is in the reverse order of chemical shift approximately. The reverse order represents that the edge-width is inversely proportional to ionic character for this series.

\section{REFERENCES}

[1]. Gaur A., Johari A., Shrivastava B. D., Gaur D. C., Jha S. N. Bhattacharya D., Poswal A. and Deb S. K., 2011, Sadhana, 36, 339.

[2]. Bearden J A and Snyder T M, 1964, Phys. Rev.,59, 162.

[3]. Deslattes R D, Kessler Jr E G, Indelicato P, de Billy L, Lindroth E and Anton J, 2003, Rev. Mod. Phys., 75, 35.

[4]. Gupta M. K. and Nigam A. K., 1972, J. Phys. F, 2, 1174

[5]. Gupta M. K. and Nigam A. K., 1972, J. Phys. B, 5, 1790.

[6]. Gianturco F. A. and Coulson C. A., 1968, Mol. Phys., 14, 223.

[7]. Nigam A. K. and Gupta M. K., 1973, J. Phys., F 3, 1251.

[8]. Nigam A. K. and Gupta M. K., 1974, J. Phys., F 4, 1084. 
Table 1 Cobalt(II) Schiff base and 3 hydroxy Picolinamide mixed ligand complexes, abbreviation and molecular formula.

\begin{tabular}{|c|c|c|c|c|c|}
\hline $\begin{array}{l}\text { S. } \\
\text { No. }\end{array}$ & Complex & $\begin{array}{l}\text { Co(II) mixed ligand } \\
\text { Complexes }\end{array}$ & Abbreviation & $\begin{array}{l}\text { Molecular } \\
\text { Formula }\end{array}$ & $\begin{array}{l}\text { Molecular } \\
\text { Weight } \\
\text { (in amu) }\end{array}$ \\
\hline 01 & Co 1 & $\begin{array}{l}\text { Co(II) 3- } \\
\text { hydroxypicolinamide -4- } \\
\text { (phenyl(phenylimino) } \\
\text { methyl ) benzene-1,3- } \\
\text { diol }\end{array}$ & {$[\mathrm{Co}(\mathrm{HPA})(\mathrm{PPIMBD})] \mathrm{H}_{2} \mathrm{O}$} & $\mathrm{C}_{25} \mathrm{H}_{19} \mathrm{O}_{4} \mathrm{~N}_{3} \mathrm{Co} .2 \mathrm{H}_{2} \mathrm{O}$ & 520.0 \\
\hline 02 & Co 2 & $\begin{array}{l}\text { Co(II) 3- } \\
\text { hydroxypicolinamide -4- } \\
\text { (phenyl(p-tolylimino) } \\
\text { methyl) benzene-1,3- } \\
\text { diol }\end{array}$ & {$[\mathrm{Co}(\mathrm{HPA})(\mathrm{PTIMBAD})] \mathrm{H}_{2} \mathrm{O}$} & $\mathrm{C}_{26} \mathrm{H}_{21} \mathrm{O}_{4} \mathrm{~N}_{3} \mathrm{Co} .2 \mathrm{H}_{2} \mathrm{O}$ & 534.0 \\
\hline 03 & Co 3 & $\begin{array}{l}\text { Co(II) 3- } \\
\text { hydroxypicolinamide -4- } \\
\text { ((4-chlorophenylimino) } \\
\text { (phenyl) methyl) } \\
\text { benzene-1,3-diol }\end{array}$ & {$[\mathrm{Co}(\mathrm{HPA})(\mathrm{CPIPMBD})] \mathrm{H}_{2} \mathrm{O}$} & $\mathrm{C}_{25} \mathrm{H}_{18} \mathrm{O}_{4} \mathrm{~N}_{3} \mathrm{ClCo.} 2 \mathrm{H}_{2} \mathrm{O}$ & 554.5 \\
\hline 04 & Co 4 & $\begin{array}{l}\mathrm{Co}(\mathrm{II}) 3 \text { - } \\
\text { hydroxypicolinamide -4- } \\
\text { ((4-nitrophenylimino) } \\
\text { (phenyl) methyl) } \\
\text { benzene-1,3-diol }\end{array}$ & {$[\mathrm{Co}(\mathrm{HPA})(\mathrm{NPIPMBD})] \mathrm{H}_{2} \mathrm{O}$} & $\mathrm{C}_{25} \mathrm{H}_{18} \mathrm{O}_{6} \mathrm{~N}_{4} \mathrm{Co} .2 \mathrm{H}_{2} \mathrm{O}$ & 565.0 \\
\hline 05 & Co 5 & $\begin{array}{l}\text { Co(II) 3- } \\
\text { hydroxypicolinamide -4- } \\
\text { ((4-methoxyphenylimino } \\
\text { ) (phenyl) methyl) } \\
\text { benzene-1,3-diol }\end{array}$ & {$[\mathrm{Co}(\mathrm{HPA})(\mathrm{MPIPMBD})] \mathrm{H}_{2} \mathrm{O}$} & $\mathrm{C}_{26} \mathrm{H}_{21} \mathrm{O}_{5} \mathrm{~N}_{3} \mathrm{Co} .2 \mathrm{H}_{2} \mathrm{O}$ & 550.0 \\
\hline
\end{tabular}

Table 2 XANES data for the K-absorption edge of cobalt(II) Schiff base and 3 hydroxy Picolinamide mixed ligand complexes.

\begin{tabular}{|l|l|l|l|l|l|l|l|l|}
\hline $\begin{array}{l}\text { S. } \\
\text { No. }\end{array}$ & Mixed Complexes & $\begin{array}{l}\mathrm{E}_{\mathrm{K}} \\
(\mathrm{e} \mathrm{V})\end{array}$ & $\begin{array}{l}\mathrm{E}_{\mathrm{A}} \\
(\mathrm{e} \mathrm{V})\end{array}$ & $\begin{array}{l}\text { Chemical } \\
\text { Shift } \\
(\mathrm{e} \mathrm{V})\end{array}$ & $\begin{array}{l}\text { Shift of } \\
\text { principal } \\
\text { Absorption } \\
\text { Maxima } \\
(\mathrm{e} \text { V })\end{array}$ & $\begin{array}{l}\text { Edge } \\
\text { Width } \\
(\mathrm{e} \text { V) }\end{array}$ & $\begin{array}{l}\text { ENC } \\
\text { (Electron/ } \\
\text { Atom })\end{array}$ & $\begin{array}{l}\text { Percentage } \\
\text { Covalency }\end{array}$ \\
\hline 01 & Cobalt Metal & 7708.01 & 7722.00 & - & - & 13.99 & - & 51.81 \\
\hline 02 & Co 1 & 7714.45 & 7726.36 & 6.44 & 18.35 & 11.91 & 1.14 & 44.11 \\
\hline 03 & Co 2 & 7716.79 & 7725.68 & 8.78 & 17.67 & 8.89 & 1.35 & 32.92 \\
\hline 04 & Co 3 & 7714.74 & 7725.33 & 6.73 & 17.32 & 10.59 & 1.17 & 39.22 \\
\hline 05 & Co 4 & 7714.92 & 7725.90 & 6.91 & 17.89 & 10.98 & 1.19 & 40.66 \\
\hline 06 & Co 5 & 7717.11 & 7726.57 & 9.10 & 18.57 & 9.46 & 1.38 & 35.06 \\
\hline
\end{tabular}



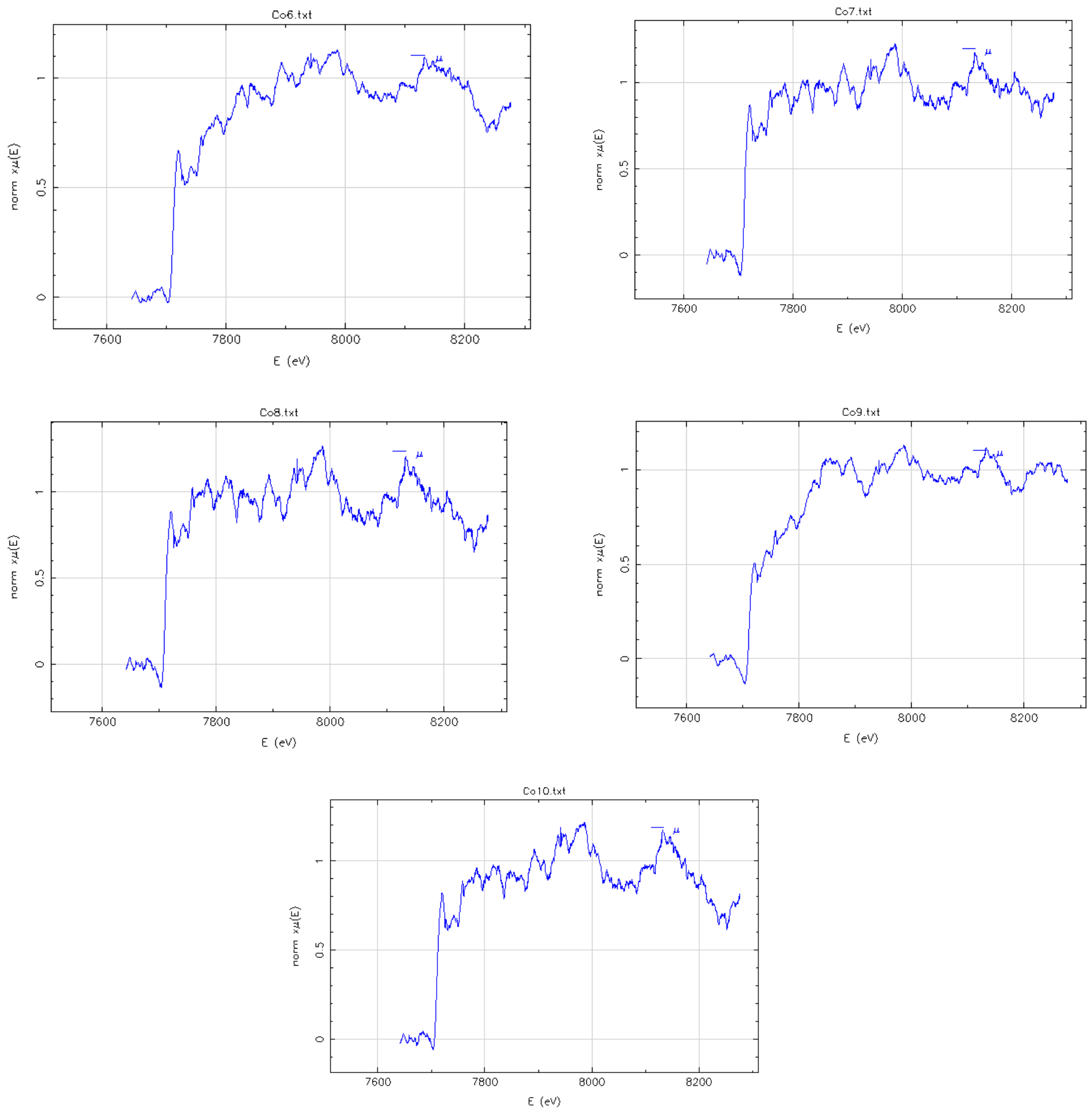

Fig. 1 XAFS spectra of cobalt (II) Schiff base ligand and 3-hydroxy Picolinamide mixed ligand complexes 

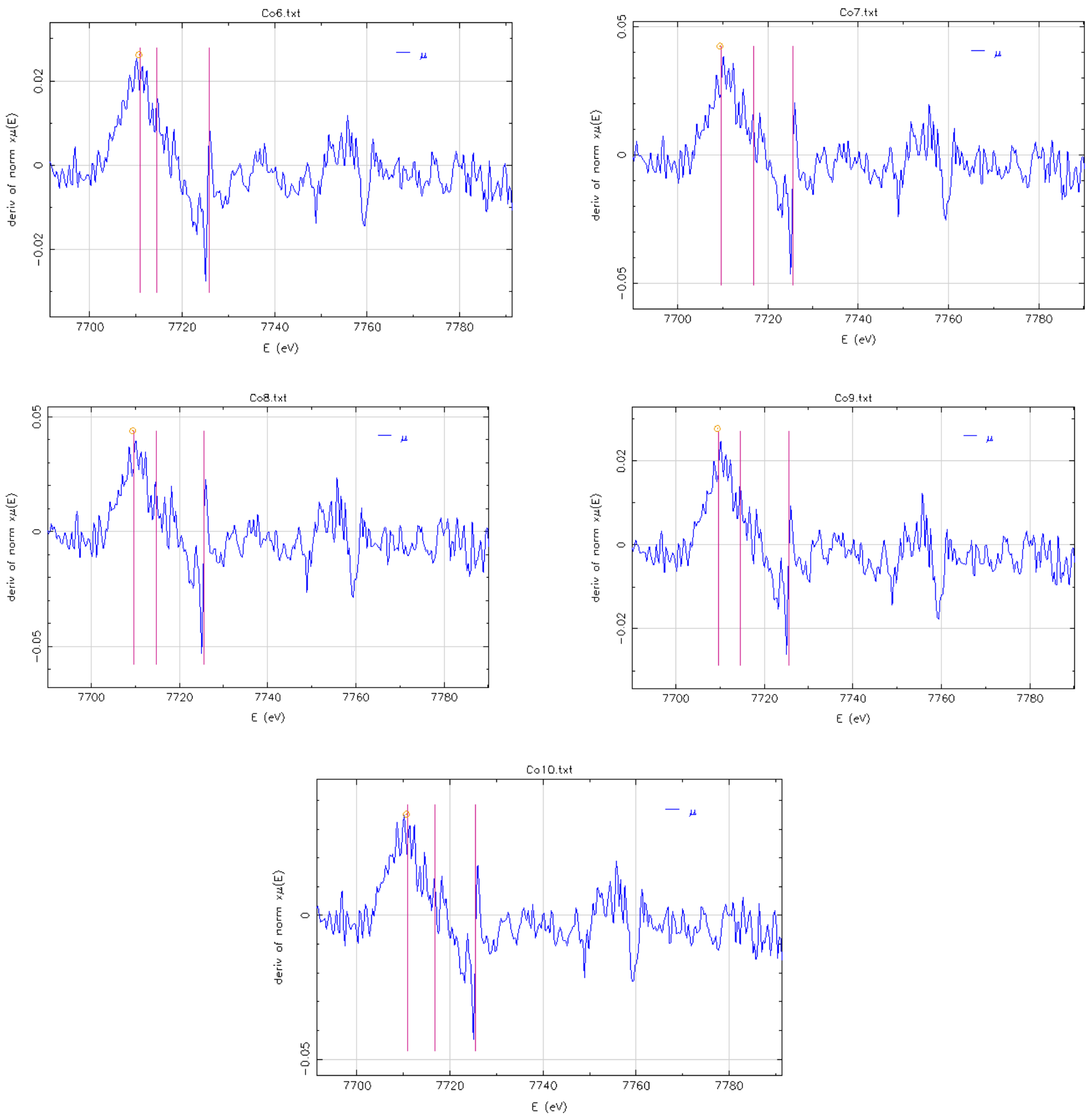

Fig. 2 Derivative of XAFS spectra of cobalt (II) Schiff base ligand and 3-hydroxy Picolinamide mixed ligand complexes indicating position of absorption edges $\mathrm{K} 1$ and $\mathrm{K} 2$ and principal absorption maxima A. 